\title{
Pemanfaatan Kababaji (Kalkulator Berat Badan Janin) Pada Ibu Hamil sebagai Kontrol Kesehatan Janin
}

\author{
Zata Ismah ${ }^{1}$, Mhd Furqan ${ }^{1}$ \\ ${ }^{1}$ Fakultas Kesehatan Masyarakat, Universitas Islam Negeri Sumatera Utara, JI. IAIN No. 1 Medan \\ Kota Medan, 20235, Indonesia
}

Corresponding author: Zata Ismah, Fakultas Kesehatan Masyarakat, Universitas Islam Negeri Sumatera Utara, JI. IAIN No.1 Medan. E-mail : zataismah@uinsu.ac.id

\section{Riwayat Artikel}

Diterima: 2021-04-29

Disetujui: 2021-05-14

Dipublikasi: 2021-10-01

\section{Keywords}

Aplikasi, Kesehatan Janin, ,

Kababaji, Ibu Hamil

\begin{abstract}
To overcome the problem of low fetal weight (BBJR), then neonatal health problems can be resolved early. Recording, reporting and early intervention are necessary to avoid these losses. Including awareness of pregnant women in terms of fetal health status is an important key in the preventive paradigm. Therefore it is necessary to provide a light and simple application that pregnant women can use independently to find out whether their fetal weight status is normal or not. The activity of using this application is targeted at 164 pregnant women who have their pregnancy checked by midwives / obstetricians in Palembang City. The results of this activity are very helpful for mothers to know their fetal weight independently with the main display of the application which is very simple and easy to use; for shortcomings the operation of this application requires hardware in the form of a Personal Computer (PC). This tool will facilitate the data collection process for pregnant women with high risk, which in the future is expected to be integrated with the existing surveillance system in the health office.
\end{abstract}

\section{PENDAHULUAN}

Masa janin termasuk dalam periode 1000 hari pertama kehidupan. Periode ini sering disebut sebagai golden period atau window of opportunities di mana pada masa ini terjadi proses tumbuh kembang yang sangat cepat dan tidak terjadi pada kelompok usia lain (POGI, 2016). Intervensi yang tepat pada periode ini akan berdampak pada kualitas sumber daya manusia yang lebih baik (Kemenkes RI, 2012). Masalah yang terjadi saat ini ibu yang datang pada pemeriksaan kehamilan hanya diberikan hasil taksiran berat badan janin, kemudian diberikan interpretasi secara kualitatif oleh bidan atau dokter tanpa diberitahukan si janin kurang berat berapa gram dan perlu ditambah berapa gram (Dimiati, 2012). Masalah lainnya adalah tidak ada pencatatan berat badan janin dalam kandungan sehingga prevalensi Berat Badan Janin Rendah (BBJR) di Indonesia tidak diketahui. Pemerintah, Dinas Kesehatan, maupun lembaga riset hanya mempublikasikan angka kejadian Berat Badan Lahir Rendah (BBLR), tanpa mengklasifikasikan usia gestasi dan diagnosa pendukungnya (Ernawati, 2011; Michael, 2016; POGI, 2016). 
Kejadian berat badan janin rendah (BBJR) berdampak pada beberapa kondisi kesehatan yang merugikan (Pusponegoro, 2015). Perlu diketahui bahwa intervensi terhadap masalah BBJR juga dapat mencegah terjadinya BBLR. Dengan teratasinya masalah BBJR, maka masalah-masalah kesehatan neonatal dapat teratasi secara lebih dini(Sungkar, 2015). Oleh karena itu pencatatan, pelaporan serta intervensi sedini mungkin perlu dilakukan untuk menghindari kerugian-kerugian tersebut. Hal ini dilakukan untuk mencegah terjadinya masalah-masalah kesehatan terhadap bayi, baik ketika masih dalam kandungan maupun ketika telah dilahirkan seperti Small Gestational Age (SGA), BBLR dan lain-lain (Huda, 2013; POGI, 2016; Nuraini 2017). Intervesi yang tepat adalah pada ibu hamil memiliki persentase probabilitas memiliki BBJR yang tinggi. Oleh karena itu, diperlukan sebuah terobosan untuk mendeteksi status berat badan janin ini.

Terobosan ini dapat diwujudkan dengan membuat sebuah perangkat lunak yang mampu menghitung status seorang ibu memiliki janin dengan berat badan rendah. Dengan demikian, berdasarkan hasil pendataan tersebut dapat dilakukan intervensi secara cepat dan tepat, dan program pemerintah mengenai BBJR dapat optimal. Aplikasi kesehatan dengan menggunakan berbagai pendekatan baik melalui teknologi dan non-teknologi telah dikembangkan dan menunjukkan hasil yang positif terhadap perbaikan masalah kesehatan ibu dan anak. Berdasarkan hal tersebut, kegiatan pengabdian masyarakat yang akan dilakukan adalah menggunakan teknologi kalkulator untuk mengestimasi berat badan janin ibu hamil.

\section{METODE}

\section{A. Tahap Pembuatan Aplikasi}

Sebelum pemanfaatan aplikasi ini dilakukan penelitian terlebih dahulu untuk pembuatan apikasi. Tahap tersebut adalah :

1) Analisis berat badan janin baku dari World Health Organization (WHO). Tahap 1 ini menggunakan pendekatan penelitian kepustakaan. Penelitian kepustakaan ini dilakukan dengan mencari data berat normal Janin Asia Tenggara yang bersumber dari data WHO.

2) Pengumpulan data berat badan janin dari 600 ibu hamil. Pengumpulan data yang digunakan dalam penelitian ini diperoleh dengan mewawancarai ibu hamil yang berkunjung ke pelayanan kesehatan. Petugas kesehatan dalam penelitian ini adalah bidan atau dokter yang bertugas memeriksakan pasien. Bidan dan dokter mampu untuk melakukan pemeriksaan dengan USG (Ultrasonography). Bidan dan dokter hanya mengukur berat badan janin, usia kehamilan;

3) Pembuatan model prediksi berat badan janin berdasarkan berat badan janin penelitian. Pembuatan model prediksi ini dilakukan dengan menganalisis hasil berat badan janin dari 600 sampel dengan berat janin baku dari WHO. Dari tahapan ini didapatkan 4 model prediksi berat janin yang terdiri dari umur janin 1 - 63 hari, umur janin 64 - 91 hari, umur janin 92 - 119 hari ; umur janin 120 - 182 hari; umur janin 183 - 308 hari. 
4) Perhitungan kelayakan model prediksi berat badan janin. Kelayakan dari semua keempat model prediksi berat janin diatas berada pada $>90 \%$ (sangat baik).

\section{B. Tahapan Pemanfaatan Aplikasi}

Untuk tahap pemanfaatan dilakukan dengan tahap berikut:

1. Mendatangi klinik pemeriksaaan kesehatan kehamilan.

2. Mengumpulkan sebanyak 164 ibu hamil yang biasa melakukan pemeriksaan kesehatan diklinik target di kota Palembang.

3. Menghubungi ibu hamil kemudian diminta kesediaanya serta menginstal aplikasi ke laptop pribadi.

4. Mendampingi satu-persatu ibu hamil yang memeriksakan kehamilannya ke bidan/dokter kandungan.

5. Bersama ibu hamil, mencatat hasil pemeriksaan kehamilan berupa berat badan janin.

6. Ibu hamil yang sudah mencatat hasil pemeriksaan berat badan janinnya dipandu untuk memasukkan datanya kedalam software yang sudah terinstal ke laptop masing-masing ibu untuk mengetahui berat badan janinnya apakah masuk normal atau tidak.

7. Ibu hamil diberikan penyuluhan terkait hasil pemeriksaan kehamilannya.

\section{Tahapan Evaluasi Aplikasi}

Evaluasi kegiatan yang berlangsung selama uji coba pemanfaatan aplikasi kepada ibu hamil. Teknik evaluasi yaitu dengan wawancara kepada ibu hamil mengenai pengalamannya menggunakan aplikasi. Instrumen pengukuran menggunakan pedoman wawancara semi terbuka.

\section{HASIL DAN PEMBAHASAN}

Kababaji versi desktop adalah aplikasi sangat ringan dan bersahabat pada berbagai PC. Kababaji optimal digunakan dengan Windows 7, 8, dan 10. Berikut tampilan aplikasi :

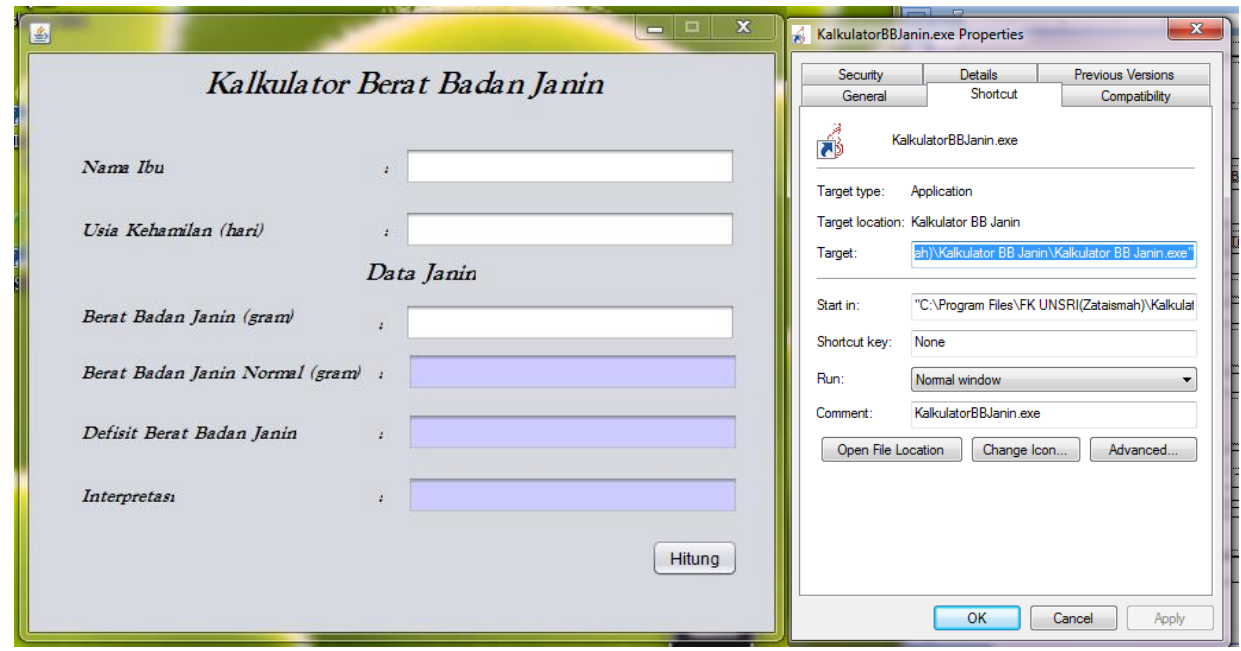

Gambar 1 : Prototype dari Aplikasi Kababaji

Adapun skenario cara penggunaanya adalah sebagai berikut : 
1. Install aplikasi kedalam PC

2. Setelah diinstall, buka aplikasi

3. Masukkan nama ibu hamil pada kolom nama ibu

4. Masukkan usia kehamilan ibu dalam hitungan hari

5. Kemudian masukkan data berat badan janin dari hasil USG dalam gram

6. Kemudian klik hitung

7. Hasil perhitungan defisit berat badan janin akan keluar pada kolom defisit

8. Kesimpulan berat badan janin akan keluar pada kolom interpretasi. Pada kolom tersebut akan dinyatakan berat badan janin normal atau rendah

Berikut gambaran Entity Relationship Diagram Aplikasi :

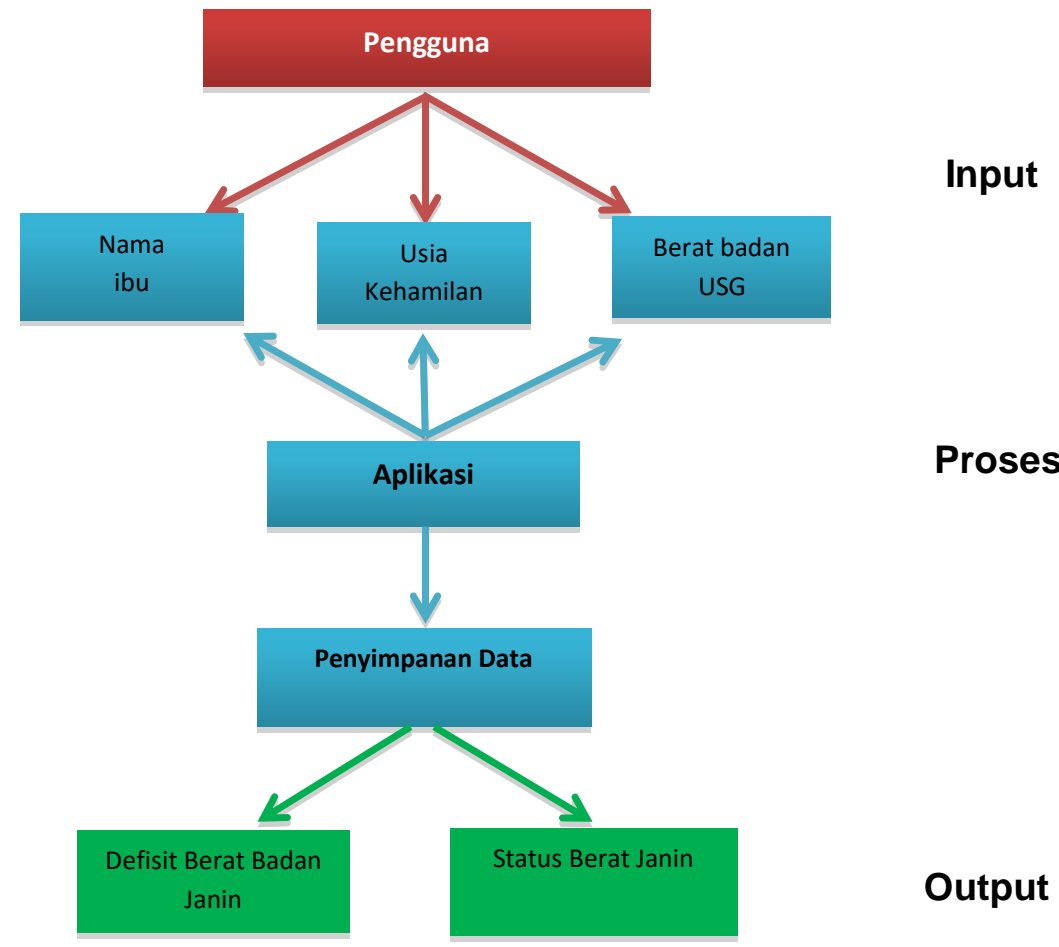

Aplikasi ini kemudian dimanfaatkan kepada 164 sampel ibu hamil. Berdasarkan hasil uji coba didapatkan :

Validitas $=\frac{\text { Banyaknya Hasil Pengujian yang Bernilai Benar }}{\text { Banyahnya Jumlah Sampel }} \times 100 \%$

$$
\begin{aligned}
& =\frac{197}{164} \times 100 \% \\
& =83,53 \%
\end{aligned}
$$

Didapatkan hasil validitas sebesar $83.53 \%$. Dengan demikian validitas aplikasi ini sangat baik (>80\%);

24 | Shihatuna: Jurnal Pengabdian Kesehatan Masyarakat (2021) 1(1) 
Hasil evaluasi berupa tanggapan kelebihan dan kekurangan aplikasi. Adapun hasil evaluasi dapat dilihat pada grafik berikut :

\section{Grafik 1. Kelebihan Software Kababaji Menurut Responden}

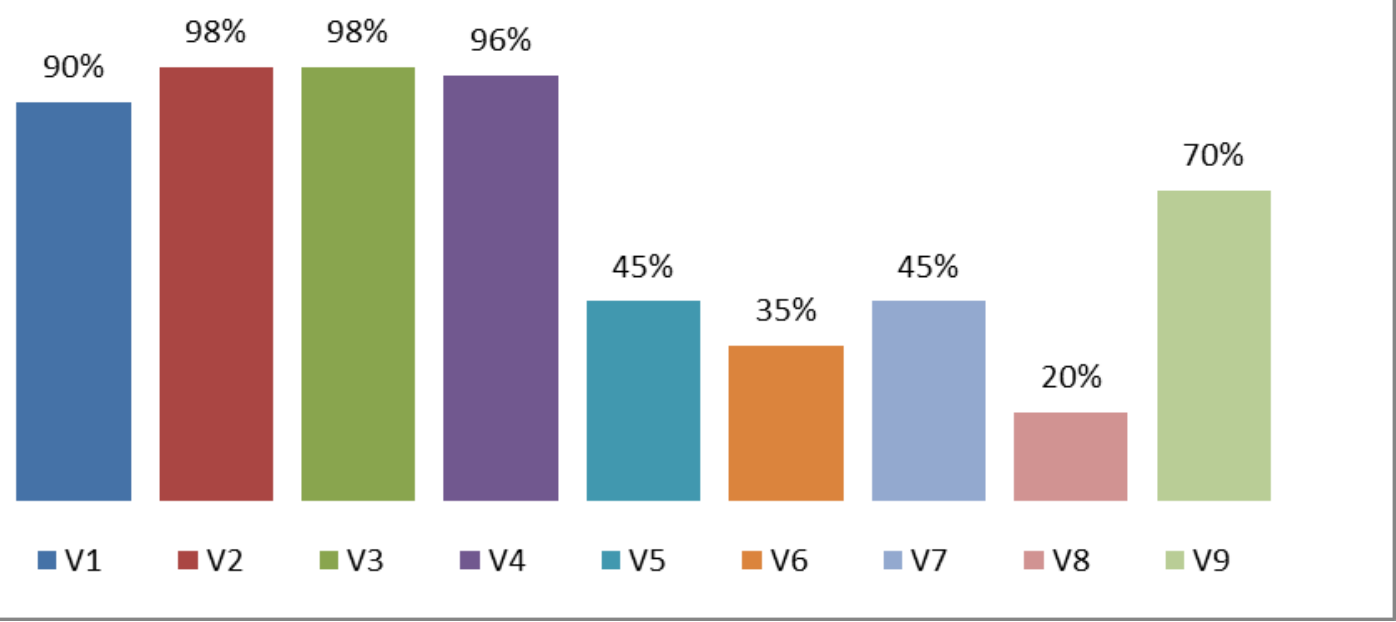

Keterangan :

V1 : Sangat membantu para ibu mengetahui berat badan janinnya secara mandiri

V2 : Tampilan utama dari aplikasi ini sangat sederhana

V3 : Mudah digunakan

V4 : Adanya riwayat perhitungan;

V5: Riwayat dapat menampung data sebanyak $\geq 200$;

V6 :Data responden dapat di salin ke Microsoft Office;

V7 : Ukuran aplikasi ringan;

V8 : Ram yang digunakan ringan

V9 : Validitas/ketepatan hitungan yang tinggi 


\section{Grafik 2. Kekurangan Software Kababaji Menurut Responden}

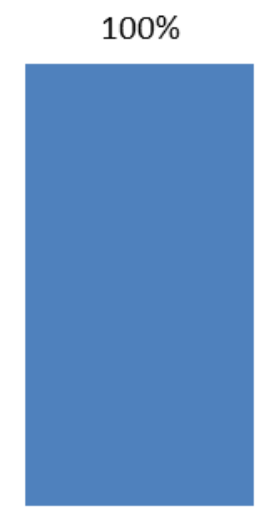

$\square \mathrm{V} 1$

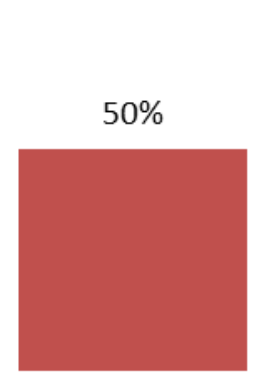

V2

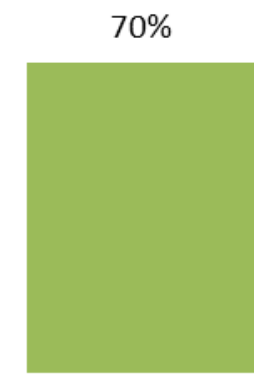

V3

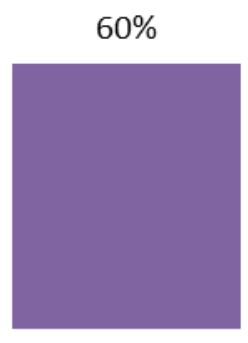

V4

Keterangan :

V1 : Membutuhkan perangkat keras berupa Personal Computer (PC);

V2 : Belum support untuk menu maximize;

V3 : Jika aplikasi ditutup, data riwayat akan hilang;

V4 : Tidak adanya Backup data;

Ke depan aplikasi KABABAJI dapat dilanjutkan versi web based dan android based. Versi ini akan langsung terhubung dengan system surveilans dinas kesehatan. Apabila telah terhubung maka sistem surveilans berat badan janin diharapkan dapat optimal dan banyak menjaring janin yang kurang berat badannya sehingga akan banyak janin yang diintervensi, dan mengurangi angka BBLR (berat badan bayi lahir rendah). Apabila kedua versi tersebut sudah terlaksana, maka aplikasi dapat langsung di distribusikan kepada stakeholder berupa Dinas Kesehatan, Tenaga Kesehatan yang berkaitan dengan KIA, dan masyarakat.

Hasil implementasi akan dilakukan pelaporan kepada pihak universitas, dinas kesehatan, dan investor. Sedangkan pelaporan hasil monitoring dan evaluasi akan dilakukan pada 2 semester pertahun. Aplikasi ini agar dapat dirasakan kebermanfaatnya, Inovasi ini akan didistribusikan melalui beberapa tahap berikut :

1. Advokasi kepada Dinas Kesehatan Kota/Kabupaten dengan membuat sebuah media Policy Brief dari hasil pengembangan aplikasi KABABAJI

2. Tahap selanjutnya Aplikasi versi web based akan diaplikasikan menjadi widget di Web Dinas Kesehatan atau web Puskesmas/Klinik Swasta bagi yang memiliki. Puskesmas dan Klinik Persalinan wajib mengakses web tersebut setiap kali kunjungan kehamilan (K1 s.d K4)

3. Untuk aplikasi versi desktop juga disebarkan kepada Puskesmas dan Klinik swasta sebagai solusi apabila jaringan internet bermasalah ataupun Puskesmas atau klinik swasta yang tidak memiliki akses internet. Penyebaran aplikasi dengan dimasukkan 
kedalam CD-R untuk diinstal dimasing-masing komputer puskesmas dan Klinik Persalinan

4. Untuk aplikasi versi android, dibagikan untuk sasaran masyarakat yang ingin mengetahui berat janinnya secara mandiri. Penyebaran kepada masyarakat akan disosialisasikan pada acara posyandu, pos ptm, penyuluhan rutin puskesmas, ataupun acara masayarakat seperti wirid, ceramah agama, maulid nabi dst. Agent yang menyebarkan aplikasi ini ke masyarakat adalah memberdayakan mahasiswa ilmu kesehatan masyaarakat yang sedang menjalani KKN, PBL, ataupun Magang.

5. Penyebaran aplikasi KABABAJI ini dicanangkan menyebar merata diseluruh puskesmas kota Medan pada 1 tahun disetujuinya aplikasi ini oleh dinas kesehatan.

6. Penyebaran aplikasi KABABAJI ini dicanangkan menyebar merata diseluruh klinik swasta pada 2 tahun disetujuinya aplikasi ini oleh dinas kesehatan.

7. Setelah aplikasi terdistribusi merata di Kota percontohan, tahap selanjutnya adalah riset analisis dampak aplikasi KABABAJI dengan estimasi kurang lebih 5 tahun. Apabila KABABAJI ini terbukti optimal, maka aplikasi akan dinaikkan ke Nasional.

8. Distribusi tingkat nasional akan bekerjasama dengan Kementrian Kesehatan Republik Indonesia. Aplikasi KABABAJI akan dipublikasikan dan disosialisasikan pada setiap konferensi dan pertemuan ilmiah penelitian nasional.

\section{KESIMPULAN}

Aplikasi KABABAJI ini teruji sangat bermanfaat untuk menghitung berat badan janin bagi penduduk Indonesia. Pengembangan dan perancangan aplikasi dilakukan dengan didahului riset yang baik. Validitas yang didapatkan adalah sebesar $83.53 \%$. Dengan demikian validitas aplikasi ini sangat baik (>80\%). Aplikasi ini menjawab kebutuhan bagi semua tingkat pengguna mulai dari Dinas Kesehatan hingga Masyarakat biasa.

Masa depan aplikasi KABABAJI ini dibutuhkan kerjasama dengan berbagai pihak. Kerjasama tersebut diantaranya komitmen Dinas Kesehatan. Dinas Kesehatan dibutuhkan komitmennya dan pengawasannya agar aplikasi ini terus dipakai oleh puskesmas dan klinik swasta. Selanjutnya diperlukan kerjasama kesediaan klinik swasta untuk menginstal aplikasi KABABAJI ini dan memanfaatkannya pada saat menghitung taksiran berat badan janin. Kemudian tidak luput juga kerjasama dengan berbagai universitas untuk memberdayakan mahasiswa sebagai agent penjaga keberlangsungan aplikasi. Pihak universitas dalam hal ini juga sebagai pusat studi penelitian untuk evaluasi efektifitas dari KABABAJI. Terakhir dibutuhkan kerjasama merambah lintas keilmuan berupa pusat penelitian IT, agar KABABAJI dapat dilanjutkan pengembangannya ke versi WEB Based dan Android Based. Dengan demikian, manfaat Aplikasi ini akan semakin banyak dirasakan ke semua pelosok nusantara.

\section{UCAPAN TERIMA KASIH}

Ucapan terimakasih kepada Prof. Suryadi Tjekyan, D\&TMnH.,M.P.H yang banyak membantu ide hingga teknis dalam pembuatan aplikasi serta pendistribsuian aplikasi ini. 


\section{REFERENSI}

Cunningham, F. G., Hauth, J. C., Leveno, K. J., Gilstrap, L., Bloom, S. L., \& Wenstrom, K. D. W. (2005). Obstetrics 22ND EDITION. United States of America: Medical Publishing Division.

Dimiati, H. (2012). Pertumbuhan Janin Terhambat Sebagai Faktor Risiko Penyakit Kardiovaskular. Jurnal Kedokteran Syiah Kuala, 12(3).

Ernawati, F., Kartono, D., \& Puspitasri, D. S. (2011). Hubungan Antenatal Care Dengan Berat Badan Lahir Bayi Di Indonesia (Analisis Lanjut Data Riskesdas 2010). Gizi Indonesia.

Huda, W. N. (2013). Pertumbuhan Janin Terhambat (PJT) Sebagai Faktor Risiko Kematian Neonatus. Skripsi.

Kemenkes RI. (2012). Penuhi Kebutuhan Gizi pada 1000 Hari Pertama Kehidupan. Jakarta: Depkes RI. Retrieved from www.depkes.go.id

Michael, O., \& Stephanie, O. (2016). Intrauterine Growth Retardation (IUGR): A Case Report. Academic Journal of Pediatrics and Neonatology. California: Juniper Publisher.

Nuraini, L. A. P. (2017). Gambaran Faktor Penyebab "Intrauterine Growth Restriction" (IUGR) di Rumah Sakit Khusus Ibu dan Anak Sadewa Sleman. Skripsi.

Ohlsson, A., \& Shah, P. (2014). Literature Review of Low Birth Weight, Including Small for Gestational Age and Preterm Birth. Evidence Based Neonatal Care and Outcomes Research. Toronto Public Health.

POGI. (2016). Pedoman Nasional Pelayanan Kedokteran PENGELOLAAN KEHAMILAN DENGAN PERTUMBUHAN JANIN TERHAMBAT. Indonesia: Perkumpulan Obstetri dan Ginekologi Indonesia Himpunan Kedokteran Feto Maternal.

Pusponegoro, H. D. (2015). Brain Development in Infant Born with Small for Gestational Age. Retrieved from www.nestlenutrition-institute.org.

Sungkar, A. (2015). The Etiology and Prevention Strategy of Small for Gestational Age from Obstetrician View. Retrieved from www.nestlenutrition-institute.org.

WHO. (2014). Low Birth Weight Policy Brief. Retrieved from www.who.int: http://www.who.int/nutrition/topics/globaltargets_lowbirthweight_policybrief.pdf 